Meta

Journal des traducteurs

Translators' Journal

\title{
Institutional Multilingualism in NGOs: Amnesty International's Strategic Understanding of Multilingualism
}

\section{Wine Tesseur}

Volume 59, numéro 3, décembre 2014

Traduction et plurilinguisme officiel

Translation and Official Multilingualism

URI : https://id.erudit.org/iderudit/1028657ar

DOI : https://doi.org/10.7202/1028657ar

Aller au sommaire du numéro

Éditeur(s)

Les Presses de l’Université de Montréal

ISSN

0026-0452 (imprimé)

1492-1421 (numérique)

Découvrir la revue

Citer cet article

Tesseur, W. (2014). Institutional Multilingualism in NGOs: Amnesty International's Strategic Understanding of Multilingualism. Meta, 59(3), 557-577. https://doi.org/10.7202/1028657ar
Résumé de l'article

Le plurilinguisme institutionnel est le plus souvent associé à d'importantes institutions intergouvernementales comme l'Union européenne et les Nations Unies. Le multilinguisme d'organisations non gouvernementales (ONG), cependant, est resté en grande partie invisible. Comme les organisations gouvernementales internationales (OGI), elles opèrent en traversant les barrières linguistiques. Cela soulève la question de savoir si les ONG utilisent la langue et la traduction de la même manière que les OGI. Dans le présent article, nous étudions le cas d'Amnistie internationale et ce que le multilinguisme veut dire pour cette organisation, comment il se reflète dans sa politique langagière et comment il est mis en pratique. En offrant une meilleure compréhension du cas particulier d'Amnistie internationale, cet article apporte une contribution à la traductologie institutionnelle. 


\title{
Institutional Multilingualism in NGOs: Amnesty International's Strategic Understanding of Multilingualism
}

\author{
WINE TESSEUR \\ Aston University, Birmingham, UK \\ tesseurw@aston.ac.uk
}

\begin{abstract}
RÉSUMÉ
Le plurilinguisme institutionnel est le plus souvent associé à d'importantes institutions intergouvernementales comme l'Union européenne et les Nations Unies. Le multilinguisme d'organisations non gouvernementales (ONG), cependant, est resté en grande partie invisible. Comme les organisations gouvernementales internationales (OGI), elles opèrent en traversant les barrières linguistiques. Cela soulève la question de savoir si les ONG utilisent la langue et la traduction de la même manière que les OGI. Dans le présent article, nous étudions le cas d'Amnistie internationale et ce que le multilinguisme veut dire pour cette organisation, comment il se reflète dans sa politique langagière et comment il est mis en pratique. En offrant une meilleure compréhension du cas particulier d'Amnistie internationale, cet article apporte une contribution à la traductologie institutionnelle.
\end{abstract}

\begin{abstract}
Institutional multilingualism is most often associated with large intergovernmental institutions such as the European Union and the United Nations. Institutional multilingualism in non-governmental organisations (NCOs), however, has remained invisible to a large extent. Like international governmental organisations (IGOs), NGOs operate across linguistic borders. This raises the question whether NGOs use language and translation in the same way as ICOs. The present article takes Amnesty International as a case study, and explores what institutional multilingualism means for this organisation, how it is reflected in its language policy, and how it is put into practice. By gaining insight into the particular case of Amnesty International, this article aims to make a contribution to institutional translation studies.
\end{abstract}

\section{KEYWORDS/MOTS-CLÉS}

multilinguisme, politique linguistique, traduction institutionnelle, ONG, langues officielles multilingualism, language policy, institutional translation, NGOs, official languages

\section{Introduction}

In our globalised world, countries must deal with problems that cross national borders. To deal with these global problems, many international organisations have been established during the twentieth century. Both the number of international governmental organisations (IGOs) and the number of non-governmental organisations (NGOs) have increased exponentially. Whereas in 1909 there were 37 IGOs and 176 NGOs, the Yearbook of International Organisations (YIO) 2014-2015 counts 7,756 IGOs and 59,383 NGOs (Union of international associations 2014). The increase in global institutional structures is often seen as a visual manifestation 
of globalisation. Most of these organisations have an effect not just on individual nations, but on the world, and thus they are powerful and important providers and users of information (Cronin 2003: 109). Power is exercised through language use and by making strategic choices about what information is to be made available and in which languages. It is here where the importance of translation comes into play. Governments and organisations can regulate people's access to or exclusion from public life and services through translation policies (Meylaerts 2012: 165).

Institutional multilingualism in organisations is a common phenomenon in today's global world. The concept refers to an institution's policies and use of languages, both for internal and external communication (Baaij 2012). The European Union (EU) and the United Nations (UN) are well-known examples of organisations that have defined their institutional multilingualism by enumerating official and working languages in their institutional policies. These policies, and the organisations' translation and interpreting practices have been studied from a variety of perspectives. Arzoz (2008), for example, addresses the challenge of respecting linguistic diversity in the EU from sociolinguistic and sociological perspectives, as well as discussing legal aspects. Duchêne (2008) focuses on the construction of linguistic minorities by the United Nations, basing his study on a thorough survey of the UN archives. Tosi (2003) looks at multilingualism from a Translation Studies point of view, addressing the relationship between multilingual translation and the phenomenon of languages in contact in the European Union. Baigorri-Jalón (2004) traces the history of interpreting at the United Nations, by examining original documents and oral testimonies. Other studies present a more contemporary insiders' view of translation practices at these institutions. For example, Wagner, Bech et al. (2002) discuss the roles of different EU institutions and their translation services, and other practical issues such as what the day-to-day job of a translator involves and how to become an EU translator. Cao and Zhao (2008) describe linguistic and institutional features of UN translation. Their study argues that translation for the UN is a specialized activity. Taking an ethnographical and anthropological point of view, Koskinen (2011) concludes that the European Commission has a culture of its own, in which translators are mediators between their own national culture and that of the EU.

Research on translation policies and practices at NGOs has attracted far less attention, even though there are approximately seven times more international NGOs than there are IGOs, as the numbers presented above illustrate. Yet research on IGOs cannot be considered representative of all types of international organisations. IGOs and NGOs exercise different functions and they originate from very dissimilar historical backgrounds. Thus, they may use language and translation in a different way, and attribute different meanings to the concept of institutional multilingualism. Furthermore, NGOs often work with volunteers instead of having in-house translators. This raises questions concerning translation ethics and activism (for example, to what extent do translators identify with the organisation they are working for?), as well as translation quality, consistency, deadlines, and the use of translation guidelines (see Pym 2012). For these reasons, institutional multilingualism at NGOs needs to be explored in depth.

The present article looks at how institutional multilingualism is understood by NGOs and IGOs, and how the concepts of institutional multilingualism and official and working languages are used in policy documents. After briefly outlining the 
historical foundations of a number of international organisations, the article focuses on institutional multilingualism and translation at one NGO in particular, namely Amnesty International (AI). It demonstrates how the NGO has come to attach more importance to multilingualism and translation over the years in light of the organisation's growth and impact. Attention is paid to how language is used as a strategic tool, and how recent developments affect translation policies at AI.

\section{Data and methodology}

The research findings presented in this article are part of an ongoing doctoral project on translation policies at AI. The research contributes to sociological approaches to translation, more particularly to research on institutional translation. Following Spolsky (2004) and González Núñez (2013), it defines translation policy as comprising translation management, translation practices, and translation beliefs. Translation policy forms part of language policy. Documenting language policy automatically entails taking decisions on the use or non-use of translation (González Núñez 2013: 475). Thus, "there is no language policy without a translation policy" (Meylaerts 2010: 229). By looking at different sets of data collected through ethnographic fieldwork, the project explores which translation policies are in place at AI, and how these are reflected in translations produced at this institution. Ethnographic fieldwork was conducted at three AI offices: two months at Amnesty International Vlaanderen (AIVL) in the spring of 2012, two months at Amnesty International Language Resource Centre Head Office Madrid (AILRC-ES) also in the spring of 2012, following the fieldwork at AIVL, and one month at Amnesty International Language Resource Centre Paris (AILRS-FR) in the spring of 2013. Various methods of ethnographic data collection were used, such as participant observation, informal discussions on the topic of translation with several staff members, semi-structured interviews, and the collection of internal policy documents and other relevant documents. Furthermore, a fieldwork diary was kept and a corpus of originals and translations of various AI texts was compiled. These texts were analysed in order to gain insight into how translation policies impacted on the actual translations. A case study on the translations of AI press releases was published in Tesseur (2013).

We focus here on translation management at AI by analysing internal policy documents. These documents are evidence of translation management and can be conceptualised as explicit policy (González Núñez 2013). The use of the concept of policy here is similar to a more traditional interpretation of policy as "a set of plans or actions agreed on by a government, political party, business, or other group." We describe how AI's institutional multilingualism and translation policy developed over the years, and how its policy has been put into practice. The data used in this article consists mainly of internal policy documents and additional information collected through interviews with translators and other AI staff members. Interview data is kept to a minimum, since the focus is on the institutional framework as expressed in AI's policy documents rather than on the translators themselves. 


\section{Institutional multilingualism and official and working languages in international organisations}

\subsection{Institutional multilingualism and official language use}

Institutional multilingualism requires that an institution identifies two or more languages as official (see Meylaerts 2010: 227). In the European Union and the United Nations, institutional multilingualism is built into the foundational charters, which include a clause enumerating the official and working languages. This phenomenon is often referred to as foundational multilingualism (see Cronin 2009: 127; Joscelyne 2000: 82; Koskinen 2008: 28). Foundational multilingualism can be conceptualised as a linguistic configuration of diplomacy, balancing the interests of the different parties involved (Joscelyne 2000: 82). Joscelyne points out that, for this reason, foundational multilingualism "will rarely be questioned or modified in response to market or other external pressures" (2000: 83). It is a particular type of institutional multilingualism that is highly resistant to change.

Making a language official can mean different things. It may relate to the language's use in public space or in documents, for example. Also, declaring a language official does not guarantee it will be practised, or that other languages will not be used (Shohamy 2006: 61). Degrees to which official language use is implemented may differ from organisation to organisation. Our interest here is in how the implementation of official language use differs in IGOs and NGOs. Pym (2008: 79) identifies three types of strategies for cross-cultural communication within international nonprofit organisations: (1) language learning, where an institution has one or two official languages and speakers of other languages are obliged to learn and operate in them. Examples of institutions which apply this strategy are the OECD and NATO; (2) multilateral translation, where all languages are translated into all other languages, as happens in the EU; and (3) translation from a central language, where multilingual ideals are reduced by introducing a division between internal communication performed in one or two working languages, and translation used for communication with the "client cultures." Pym (2008: 81) argues that this third type of strategy "would seem to be the trend not only of international non-profit institutions such as we find them, but also of most multinational marketing." However, he points out that the strategy is also often used by large institutions that claim to have a multilingual policy, such as the EU (Pym 2008: 81). This article contributes new insights by discussing how official language use as part of institutional multilingualism is implemented in the EU, at the UN and at AI, and, in addition, touches on some elements of internal communication at Oxfam.

\subsection{Official and working languages in IGOs}

The constituent Charter of the United Nations was drawn up in five languages in 1945 (Chinese, English, French, Russian, and Spanish), with the five texts considered to be equally authentic. ${ }^{2}$ The UN's General Assembly recognised these five languages as the organisation's official languages in 1946, whereas French and English were identified as the working languages. The UN's position on multilingualism, as stated in General Assembly resolution 50/11 on multilingualism, ${ }^{3}$ is designed to ensure that "each Member State of the Organization, irrespective of the official language in which 
it expresses itself, has the right and duty to make itself understood and to understand others." Thus, even if the number of official languages in the UN is limited, the underlying idea is one of language equality. The UN's multilingual policies have gradually changed over time. In 1948 Spanish was added as a third working language, and in 1968 Russian was added as a working language of the General Assembly, meaning that all official languages except Chinese were at that time working languages. In 1973, the General Assembly decided to make Chinese a working language as well, and to add Arabic as both an official and working language. The distinction between official and working language was abolished by the General Assembly in 1983, giving all six languages equal status. ${ }^{4}$ Other UN bodies have also implemented this language policy over time. Both the Security Council, and the Economic and Social Council use the six languages as official and working languages. The UN's Secretariat, however, only uses English and French as working languages. ${ }^{5}$

The use of six working languages in the different bodies has particular consequences for formal meetings. When English and French were the only working languages of the General Assembly, speeches at meetings could be delivered in any of the other official languages, but were interpreted exclusively into English and French. ${ }^{6}$ Now, however, simultaneous interpreting is provided in all of the working languages, bringing with it a significant increase in interpreting work (see note 5). In terms of translation, the decision to use the official languages as working languages in particular UN bodies has had considerable consequences as well, even though the working languages of the UN Secretariat are still limited to two. These two working languages are used for the drafting of documents (especially English). As they are the main source languages, knowledge of at least one of them is a fundamental requirement for UN translators (Cao and Zhao 2008: 43). ${ }^{7}$

EU institutions limit the number of working languages in order to keep the amount of translation work manageable. Regulation No 1 that determines the languages to be used by the European Economic Community dates back to 1958. It set out the official and the working languages of the European Union: Dutch, German, French, and Italian, the languages of the six founding Member States (Wagner, Bech et al. 2002: 5). The Regulation has been amended several times over the years, adding the official languages of new member states. In this way, the principle of equality was maintained through language. Institutional multilingualism for the EU is a fundamental principle meaning "equal rights for all languages," and all laws and outgoing documents are thus drafted in all official languages (Wagner, Bech et al. 2002: 1). For the EU, "allowing citizens and institutions to understand legal documents and other relevant information in their language is a prerequisite not only for the proper functioning of the institutions but also for the democratic legitimacy of the Union" (Stecconi 2010: 154).

The institutions of the EU now have 24 official and working languages. However, the working languages of the European Commission are limited to English, French and German. ${ }^{8}$ The latter, also called "procedural languages," are the languages in which documents must be provided before they can be adopted at meetings. Yet as Wagner, Bech et al. (2002: 10) point out, there is no legal basis for this concept. Procedural languages are often used for communication between EU staff, again without any formal agreement. A clear distinction can be observed in language use at the formal level, where the mother tongue is used, and at the informal level, where 
staff use English, French or, to a lesser extent, German (Stecconi 2010: 147). O'Driscoll (2001: 486) suggests that on the informal level, the use of languages other than English or French symbolises a lack of co-operation and may come across as obstructive. Thus, staff members opt for English and French, in order to show their willingness to cooperate. It could be argued that the equal status of languages on the formal level in fact contributes to the marginalisation of many of them in everyday use (O’Driscoll 2001: 486).

The EU and the UN are thus both organisations that maintain foundational multilingualism and identify official and working languages in their foundational charters. As Joscelyne (2000) argues, this type of multilingualism is a founding principle and resistant to change. Even though the number of EU official languages, for example, has increased significantly, the EU has maintained its principle of linguistic equality. Yet because concepts such as "procedural languages" are not clearly defined, some variation in exactly how these language policies are implemented is possible.

\subsection{Official and working languages in NGOs: working languages and discrimination}

English as a lingua franca in informal institutional settings is used in many international organisations. In the context of NGOs, many of which are fighting for human rights and equality, the imposition of a lingua franca could be perceived to be in contradiction to some of the core values of these organisations. For example, staff may consider the use of English to be limiting, even discriminatory.

A study on the role of language in international communications at Oxfam shows that many employees find that the priority given to English creates a roadblock to their careers (Lehtovaara 2009). Although Oxfam has four official languages (English, French, Portuguese, and Spanish), many employees feel that the four languages are not treated equally and priority is given to English. Oxfam's headquarters uses primarily English, and translations often become available at a later point in time, or not at all (Lehtovaara 2009: 93). The primary use of English can be explained by the fact that it was Oxfam's only official language until 1991, when the organisation decided its communication strategy should reflect the diversity of the organisation, taking into account differences and embracing them. Employees who took part in Lehtovaara's study (2009) indicated that while they feel Oxfam has taken steps to become more linguistically diverse, there are still many areas that need improvement. The fact that Oxfam headquarters continues to communicate mainly in English is perceived by staff to be discriminatory to some employees. For example, one can only apply to an international post if he or she has an in-depth command of English (Lehtovaara 2009: 87).

This feeling of discrimination resulting from a focus on English in the head office has been noted previously at AI by Hopgood (2006). AI identified its four official languages in the 1980s as Arabic, English, French, and Spanish. Yet its International Secretariat (IS) in London used English as its working language. ${ }^{9}$ Hopgood (2006: 176) reported that this resulted in a largely English-speaking and UK staff at the IS, although the organisation presented itself as global, like Oxfam. The preference for using English meant that only non-native speakers with a strong enough mastery of 
written and oral English moved to London to work at the IS, and they were rarely from the poorer classes in their own countries. Equal opportunity was thus not offered to people from different socio-economic and cultural backgrounds.

The English and UK bias also had a negative influence on AI's work. As the IS was the place where most research was carried out (whereas national sections were responsible for campaigning), the consequence of such an English bias was that most of the researchers were from the UK and did not speak the local languages of the areas they were researching (Hopgood 2006: 132). This situation was also due to AI's Work On Own Country rule (WOOC) that prohibited researchers from working on their own country for neutrality reasons. WOOC thus made it difficult to attract grassroots activists from divergent socio-economic backgrounds. Instead, AI attracted most often members from a small educated urban elite, who were Westernised to a great extent and had a good command of English (Hopgood 2006: 174). The focus on English was also limiting in terms of AI's international membership. AI has remained a very white organisation in terms of both members and staff throughout the years. More recently, the organisation has implemented a number of steps to make its international and global identity more prominent. AI's language strategy is an integral part of these efforts. Moreover, the changes being implemented diminish the discriminatory aspect of the use of English as described by Hopgood (2006). These issues are discussed in more detail in 4.3.

\subsection{Strategic language use and communication}

The previous sections have demonstrated that multilingual language use in NGOs and IGOs share similarities on a general level. Both types of organisations select a number of official languages between which they translate, while reducing the amount of internal translation by using "working languages." The definition of "working language" and the particular circumstances under which these languages are used are often not clear. NGOs and IGOs wish to maintain the principle of language equality in their official policy documents, yet they realise that a high number of "working languages" is not feasible in practice. Thus, there is a difference between language management as described in institutional documents, and language practice as it develops in the working environment.

When looking beyond the general level of multilingual language use, communication strategies retained by NGOs and IGOs appear to be quite different. These differences are the result of the different foundations and functions of IGOs and NGOs. The use of official languages at IGOs far exceeds the use of official languages at NGOs like Oxfam and AI. As has been pointed out, both these NGOs have four official languages; nevertheless, their headquarters work mainly in English, which generates concern over equality and discrimination issues within the organisation. The fact that NGOs nevertheless opt to work with only a small number of official languages is tied to the limited funds they have available for translation. Thus, their translation services are more closely linked to their actual needs, creating a much more strategic use of language and translation (see Pym 2001). The importance for NGOs of strategic communication and language use has been demonstrated by research in journalism and communication studies. These studies have shown that as the number of NGOs has increased considerably, many aid organisations now 
co-exist and in fact compete for media attention and donor funds (Cottle and Nolan, 2007: 863). Their communication strategies have developed and changed over the years in order to answer the news media's call for faster news and a preference for regionalised news angles. For NGOs, disseminating their message through the news media remains crucial in order to maintain a high public profile and to reach potential donors and activists. As such, the translation policies and strategies of NGOs are intimately related to their communication and growth strategy. The next section describes AI's approach to multilingualism and official language translation in response to these issues. The discussion sheds light on how AI's language policy and strategy have evolved over the years as part of the organisation's goal to increase its impact and global growth.

\section{Amnesty International and institutional multilingualism}

\subsection{The early years}

Amnesty International's roots can be traced back to 1961, when British lawyer Peter Benenson published an article in The Observer on prisoners of conscience. Benenson was outraged after learning about the fate of two Portuguese students who were imprisoned for raising a toast to freedom. Benenson's article "Forgotten Prisoners" (28 May 1961) ${ }^{10}$ launched the "Appeal for Amnesty 1961," a worldwide campaign that generated a great response. ${ }^{11}$ What began as a modest campaign grew quickly into an international phenomenon, with participants all over Europe responding by forming groups and echoing the values and aspirations Benenson promoted (Wong 2012: 88). The first international meeting was organised in July 1961, with participants from Belgium, the UK, France, Germany, Ireland, Switzerland, and the USA. Here it was decided that AI would be established as a "permanent international movement in defence of freedom of opinion and religion" (see note 10). Soon after, Benenson opened an office and library in London, which would later become the IS, AI's headquarters to this day. As discussed above, the choice of London as a base for the central unit has had far-reaching consequences for multiculturalism and multilingualism within AI. It caused an unintentional focus on the use of English and a bias in favour of English-speaking and UK staff.

During the first few years, the ideas and principles of AI were received best in northern Europe, with groups and national sections opening up in Britain, Sweden, Germany, Norway, the Netherlands, and Denmark (soon followed by Austria, Belgium, and France), as well as in mainly English-speaking countries such as Australia, New Zealand, the United States, and Canada (Hopgood 2006: 56). AI's awareness of the centrality of language has been clear since 1963, when a five-man International Executive was formed. Each of the members was selected to represent a particular language or language group (English, Scandinavian, German, FlemishDutch, and French), instead of a country (Hopgood 2006: 69).

Nevertheless, only in 1974 did AI explicitly recognise the importance of communicating in languages other than English. The 1974 International Council Meeting (ICM), AI's highest regulating body, called for publishing all important information in at least English, French, and Spanish. The 1975 ICM went further, adopting a major statement on development and multilingualism that identified links between the 
two. ${ }^{12}$ These two decisions paved the way for important changes to AI's language and translation services. Documents generated at AI's headquarters were drafted in English, and translation services for French and Spanish were set up at the IS. The initial decision to start translating into these languages was based on the expectation that AI would grow considerably in Latin America and Africa. French and Spanish also covered many of the already existing AI sections at the time (Interview \#2). ${ }^{13}$ However, these three official languages are European, and the countries AI targets worldwide use many more languages. Thus, at the 1977 ICM, a core program for multilingualism was adopted, with a budget not only for French and Spanish translation, but also for language-related work in South Asia and Africa, and a general IS translation fund. In 1985, the ICM voted to add Arabic to AI's official languages. The same year, the translation services for French and Spanish at the IS were partly moved to two Decentralised Units for French and Spanish translation, Editorial Amnistía Internacional (EDAI) in Madrid, and Éditions Francophones d'Amnesty International (EFAI) in Paris. Finally, in 1997, the translation services for French and Spanish at the IS were disestablished and completely moved to the Decentralised Units.

In 1987 AI documented its language policy for the first time, after the internal Committee of Long-term Organisation and Development (CLOD) called for "the development of AI's multilingual and multicultural character" (ORG 52/01/1993). ${ }^{14}$ The language policy identified English as the organisation's working language, with English, French, Spanish, and Arabic, its official languages. ${ }^{15}$ The focus on multilingualism and multiculturalism has remained constant throughout the years. In fact, the 1989 ICM identified development and multilingualism as super-priorities, which led to the decision to establish regional language programmes for Portuguese and Asian languages, and to allocate the Arabic translation service ARABAI its own budget. ARABAI was set up as a Decentralised Unit in 1991 (first in Egypt, later in Cyprus), although it was relocated to the IS in 2000, mainly because of high operating costs (Interview \#12). Today, the Arabic language service is still part of the IS, although discussions on whether ARABAI should be re-established have continued for years.

\subsection{From language policy to strategy: language as a strategic tool for increasing impact and growth}

Once AI documented its language policy in 1987, the organisation soon started working on developing a language strategy as well. Whereas the language policy set out general principles of language use, the strategy was developed as a response to the organisation's need for adequate tools to communicate its message, while maximising the impact of its message and its work on human rights. In order to better understand the need for this language strategy, let us consider AI's vision and mission, and the ways in which these can be achieved in a globalised world. In its official statute, AI defines itself as follows:

Amnesty International's vision is of a world in which every person enjoys all of the human rights enshrined in the Universal Declaration of Human Rights and other international human rights instruments. In pursuit of this vision, Amnesty International's mission is to undertake research and action focused on preventing and ending grave abuses of these rights. (Amnesty International 2013) 
AI's work thus consists of two main elements: (1) to research facts on individual cases and patterns of human rights abuses and (2) to call on governments, international organisations, armed political groups, companies, and other non-state actors to stop these abuses. To achieve the aim of having a positive impact on human rights, it is essential for AI to maintain a high public profile in order to increase general awareness of human rights abuses and to put public pressure on governments, but also to increase the number of activists, campaigners, and donor funds. The larger the human rights organisation, the more pressure it is able to exert on governments and other organisations. It is therefore essential that AI continue to grow, especially in geographical areas where it does not yet have a large number of activists or is not present at all.

In light of this, the 1993 ICM identified the need to document a new international language policy that would cover all the existing language services: the IS, the translation and publication units, and any other AI structures with specific attention to those countries and regions that were not covered by existing AI language programmes at the time. Consequently, AI's existing language policy and language programmes needed to be reviewed. In 1991, such a review had already been carried out by the Head of the Language Programmes Unit. Some of the proposals from the first review formed the basis of new measures and practices adopted at the ICM in 1991, but they did not lead to a new language policy. As the 1993 ICM emphasised the need to formulate a new language policy and to continue to revise and reform the existing language structures, a new review was carried out, summarising the findings of the previous review and addressing remaining issues. The report of the 1993 review, produced by AI's International Executive Committee and made available to all AI sections and language programmes, stressed the need to clarify the existing conceptual framework in the new language policy, because the framework was often unclear or unable to meet the needs of AI. One of the major issues raised in the review was that the definition and roles of "official languages" and "working languages" were unclear, leading to the production of official language materials that were not proportionate to the actual needs and capacity of the organisation (ORG 33/01/1994). The review further emphasised that messages needed to be disseminated to a wider public, not just to users of the four official languages, and thus a redefinition of the roles of the different languages was required. Therefore, the review proposed to start using the term "core language" to replace the term "official language," a terminological change that was implemented in all future references to the language programmes in AI's internal reports and documents. "Core language" was defined as "a major international language shared by several countries and used by Amnesty International for communication with governments, and interpretation and documentation for international meetings" (ORG 33/01/1994). ${ }^{16}$

Despite the effort of reviewing the language programmes a second time and starting a discussion with all sections on their translation needs, little progress was made in formulating a new language policy. The 1995 ICM report outlined the findings of the language review and contained a list of basic principles that the new language policy "should" include, yet an official policy was not documented. The 2003 ICM again heralded a renewed commitment to address AI's language policy, which was then finally documented and adopted at the 2007 ICM.

Although little progress was made during fifteen years, the change in terminology proposed by the 1991/1993 review marked the start of a different and much more 
strategic use of language and translation, together with a strategic interpretation of multilingualism. The term "official language" was intended to mean that the organisation was committed to and responsible for the production of most external and internal materials in official languages, with the same budget allotted to each of the four languages (ORG 33/01/1994). By the time of the 1991/1993 language review, AI had come to realise there was no need to translate all documents into all four languages, and that a budget was also needed for translation into other languages. The use of "core language" fitted this approach, responding better to the organisation's needs and capacity. The decision also indicates AI's awareness of the consequences of using particular terminology. As described above, Oxfam has four official languages as well, yet many staff members feel that the four languages are not treated equally and that their use generates tensions and inequality among workers instead of improving communication. Yet the overall majority of staff agreed that Oxfam should continue to have four "corporate" languages, whether they be equal or not (Lehtovaara, 2009: 82). AI attempted to circumvent this confusion by changing its terminology. It would change its terminology once again, when a few years later "core language" was replaced by "strategic language," as will be discussed below.

In line with the strategic approach that aimed to make materials in more languages available, a Portuguese Programme and an Asian Language Programme were established, and the IS provided ongoing funding of translation services for non-core languages, mostly for external documents. ${ }^{17}$ However, this funding was limited, and sections had to rely on their own resources for most of their translation needs. This resulted in divergent translation practices among the various sections, with little or no communication about these practices among the sections, or between the IS and the sections. Whereas translation into the "core languages" was highly controlled and regulated by the IS and its related Decentralised Translation Units, decisions on translation into non-core languages were taken by the sections. To cater to translation needs at the local level, sections often chose to work with volunteers. Clearly, these divergent practices could not guarantee organisation-wide quality control or terminology consistency.

Although the four languages that were identified as "core" are still the main international languages used by AI today, the terminology changed again in light of the new language policy and strategy which was finally approved in 2007. The 2007 language strategy is highly focused on using language as a tool for increasing the growth and impact of AI in order to remain significant in the twenty-first century. Its main challenge is "to strengthen [AI's] impact in a multilingual world alongside finite human and financial resources" (ORG 33/002/2006). Under this language strategy, translation becomes an integral part of the communication strategy rather than an afterthought. This entails considering the appropriate source language, and producing materials in a style that is clear and easy to read. In fact, a major resolution of the language strategy is the decision to translate into and from more languages. To make clear distinctions between languages, the concepts of "core" and "non-core" languages have been replaced by "strategic" and "tactical" languages. The reason for this is that "under the core language structure historically important languages absorb the majority of AI's language resources" (ORG 50/007/2007). Resources should be made available for translation into more languages. A target language would be determined on the basis of a list of criteria and identified as a strategic or tactical 
language. The language strategy states that a language is considered as strategic when investing in that language for a substantial period of time (for example six years) would substantially contribute to the "AI aims of growth, diversity, participation and increased activism" (ORG 33/002/2006). A language is tactical when investing in that language would maximise the impact of a specific AI human rights or growth project, and the tactical language would be used for the duration of the project only.

When AI introduced this new terminology, it also for the first time distinguished between the four languages that had traditionally been its "official" or "core" languages. English, French, and Spanish were considered to be the organisation's strategic languages, whereas Arabic was a tactical language. The intention was that only documents that targeted an Arabic-speaking audience would be translated for growth or campaigns, but that governance documents would not be translated into Arabic as a matter of routine (ORG 33/001/2008). Although AI soon reconsidered its decision and changed the status of Arabic to a strategic language as well, the new terminology of strategic and tactical languages illustrates how AI's use of language and interpretation of institutional multilingualism are different from many IGOs. Prior to 2007, AI's language use and institutional multilingualism policy were similar to that of IGOs: the organisation had implemented one working language and four official languages. Interestingly, one of the drafts for the 2007 language strategy in fact comments on the need to move away from this traditional understanding of foundational multilingualism. The document states:

A language policy exists to increase an organization's impact and effectiveness in a multilingual world, despite limited resources. To promote diversity, growth, participation and activism, AI must become increasingly multilingual. It must move from a traditional policy of foundational multilingualism based around four core languages to a policy where far less is translated into far more languages and each language will be assessed in terms of its overall contribution to AI's goals. (ORG 33/002/2006)

Under the new language policy and strategy, AI thus uses language and translation in a much more strategic way that is designed to increase the organisation's impact and growth. This interpretation of multilingualism can appropriately be referred to as "strategic multilingualism," a concept that AI already used in the context of its language programme reviews in 1995 when the organisation identified "strategic multilingualism objectives" for the next few years (ORG 33/01/1995). How this approach to multilingualism developed over the years is discussed below.

\subsection{Being global and local: "One Amnesty" and "Moving closer to the ground"}

The strategic use of language goes hand in hand not only with a general communication strategy that is designed to fit a global world, but also with adapting the structure of the organisation itself. During the late 1980s and early 1990s, when AI decentralised the French and Spanish translation units and established the Portuguese and Asian Language Programs, it was making a clear move towards decentralising its translation services. The organisation aimed at a pluralistic approach, where sections and decentralised units "need not only to translate but also to adapt and to create materials suitable to their own languages and cultures" (ORG 33/01/1994). At the same time, AI stressed the need to think carefully "about the ways in which we proj- 
ect the image of AI" (ORG 33/01/1994). These considerations foreshadowed the profound changes that have been implemented since the beginning of the twenty-first century, in order to adapt the organisation to a globalised world in which news is spreading ever faster and the field of NGOs is becoming increasingly crowded and competitive. Providing localised news packages that are customer-tailored and come from a clearly profiled or "branded" organisation is necessary in order for AI, or for any other NGO for that matter, to maintain and increase its impact on human rights (see Cottle 2009).

To make sure AI remains a significant human rights organisation in the twentyfirst century, AI identified a number of key operational areas in its 2011 growth strategy: 1) funding mechanisms; 2) language, communication, and identity; 3) transparency and accountability; and 4) placing resources closer to the ground (ORG $30 / 002 / 2011)$. In terms of translation and multilingualism, it is especially areas 2 and 4 that are of importance. For communication, identity, and language, the growth strategy stresses the need to take into account the local context, and thus encourages sections to adapt documents to their needs; communication should be "in the most appropriate language and format, and available across a range of platforms" (ORG 30/002/2011). This is in line with the trend over the previous years to decentralise translation services and encourage sections and decentralised units not only to translate but also to adapt materials to their own languages and cultures.

Tesseur (2014) looks at the consequences of a localised approach to translation, and at what "adaptation" means in the context of media documents produced for AI. The translation of an AI press release is examined from a textual as well as an institutional point of view, and translation practices and output from AILRC-FR, AILRC-ES, AI Belgique Francophone, AIVL, and AI The Netherlands are compared. The article demonstrates that different translation strategies are applied to different languages and in different sections, which leads to discrepancies in the message of the different language versions of a press release that the various sections issue. Whereas AILRC-ES and AILRC-FR produce translations that reproduce the source text message, their translations are in turn localised by the sections using them, such as AI France and AI Spain. Furthermore, the study demonstrates that AI The Netherlands and AIVL, sections that are responsible for producing their own translations, adapt the press releases to their localised audiences to a higher degree.

These differing practices when it comes to translating press releases are first of all a consequence of how translation at AI is regulated, with small non-core or nontactical languages like Dutch having to provide for their own translation work. These sections do not receive any funding for translation. They decide for themselves which texts to translate and who will translate them. But the differing practices are also a consequence of AI's encouragement to national sections to adapt material, as part of AI's general move towards decentralisation that goes well beyond the decentralisation of language services. For years, the IS has been the heart of the organisation, with the permanent professional staff and especially the researchers holding much of the decision-making power (Hopgood 2006: 83). It is the IS that centralises research functions, whereas campaigning and action are decentralised and take place on the local level (see Wong 2012). However, to get researchers into closer contact with the geographical areas they are researching, and to enable rights-holders to have easier access to the organisation, AI started to implement a "move closer to the ground" 
strategy in 2013 (ORG 30/003/2013). As part of this, functions and staff of the IS have been moved to several hub-offices around the world, including Johannesburg, Dakar, Nairobi, Hong Kong, Mexico City, and Bangkok. This move allows AI to respond quickly to local developments, and to give local AI offices and structures a faster and more qualitative support service. ${ }^{18}$ In addition to the regional hubs, AI has created a number of "Centres of Expertise," among them the Language Resource Centre (AILRC; see 4.5. for a detailed discussion). All these changes are part of the vision of "One Amnesty," which strongly reaffirms the global nature of the organisation and the need for more coordination and collaboration. The new vision aims to make the organisation a truly global one on more than one level. In addition to the "move closer to the ground," great efforts have been made to integrate the financial level of the organisation, and a Global Communications Strategy has been developed consisting of six sub-strategies, one of which is the language strategy. ${ }^{19}$

For multilingualism and translation, the decentralised structure developed as part of the "move closer to the ground" initiative has two key consequences. As explained by one of the interviewees (Interview \#3), the first consequence is the production of materials locally in languages other than English, to contribute to correcting the discriminatory effect of the traditional overemphasis on the use of English. Local staff will be hired, and contents will be written in the local languages of the hubs. This change means that either AI will start translating from these languages into English or will accept that some content be produced in other languages and not translated at all. The second consequence is a more flexible approval system that will give different language sections decision-making authority. The following quotation provides more context:

You know approving something in Amnesty is very difficult, because Amnesty needs to be really careful and completely sure that something is accurate and the approval system is a nightmare. Until something is produced and finally approved, maybe just one page of paper needs to be read by ten different people, and then these ten different people will add some modifications. At the moment, everything is approved in English, so everything that is not done in English needs to be translated into English, needs to be approved in English, and then it needs to be back-translated into that language. This is the line of work. But one of the things that we are trying to implement is that, let's not approve everything in English. I mean, if something is generated in French or in Spanish, there should be someone able to say: okay, this content is correct, and I'm approving it in French, in Spanish, or in Chinese (Interview \#3).

Approving materials in languages other than English would reduce the amount of translation done within the organisation. This is critical, since AI aims to translate between more languages and needs to allocate its limited resources and funds carefully. Furthermore, to implement the changes outlined in the 2007 language strategy and to increase the amount of translation work from and into more languages, strong language and translation support is essential. For this reason, the Language Resource Centre (AILRC) was officially established in January 2011. The following section describes how translation services are organised in the context of the AILRC. 


\subsection{The language policy and strategy put into practice}

As the organisation is going through profound changes, it is difficult to provide a complete and accurate picture of how translation work is done at the moment at AI. Since the establishment of the AILRC, many changes have been implemented, and the AILRC and other translation services are still changing continuously. Figure 1 presents an organisational chart of what the structure of the translation services looked like before the 2007 language strategy was implemented. The figure presents three different groups of languages and translation services: the core languages and their translation services, which were set up by the IS, and the non-core languages, divided into "large" and "small" languages.

FIGURE 1

Organisation of translation services at Amnesty International before 2007

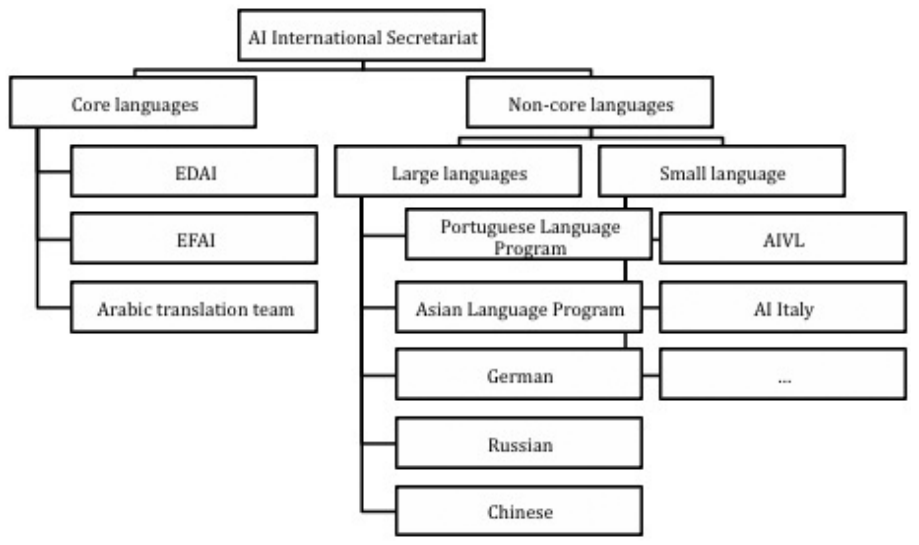

The translation services provided, respectively, for core and non-core languages under this structure were very different. AI is hoping to reduce these differences, yet the changes will take many years to implement. The differing translation practices are especially acute for small non-core languages, whose sections respond to their own translation needs. IS programmes sometimes commission translation into small non-core languages for specific reports or issues, for example a report on Haiti is likely to be translated not only into French, but also into Creole (ORG 33/001/2005). Although the new structure under the AILRC is meant to support translation in these small sections, it will take time before such support can actually be offered. In reality, at the moment all translation work into small non-core languages is still the responsibility of local sections and structures. Frequently there are no distribution plans or funds available. Translation in such cases is a key activity of staff and volunteers, as is the case for translation into Dutch at AIVL. Given that the average Dutch speaker has a good knowledge of English, staff members do not require translations of internal documents. The Flemish and the Dutch sections do not cooperate much on translation, since they have different priorities in terms of campaigning and action. Whereas regional language differences can make sharing translation less straightforward, French and Spanish translations are productively shared with various French-speaking and Spanish-speaking Amnesty International offices respectively. However, the non-need for translation at AI The Netherlands goes further than that 
of AIVL: whereas the Flemish section works with volunteer translators to translate AI's Urgent Actions, the Dutch section does not translate these texts at all and uploads the English texts ontoits website (see Tesseur 2014). ${ }^{20}$

For large non-core languages, the IS offers more support. As mentioned above, AI created Portuguese and Asian Language Programmes, both of which are largely funded by the IS, although through different structures. In addition, there also exist distinct arrangements for Chinese, Russian, and German. German-speaking countries, for example, have joined forces to organise a translation service, which is based in Munich (Interview \#3). There is no harmonisation of these structures in terms of funding, selection criteria, or translation resources. In the Portuguese Language Program (PLP), it is the Portuguese section and the IS Americas Program that decide what to translate, although they often disagree as a result of different priorities. By contrast, for Asian languages, regional sections and structures apply for funding to the Asian Language Programme (ALP), and the IS Publications Programme also undertakes some translation into Asian languages on an ad-hoc basis. Although most of the translation work at AI is done from English, translation of local materials into English is encouraged under the ALP. The most important guideline for the ALP is that the translation reflects AI's commitment to grow in reach and impact by supporting requests from countries with no sections that are considered high priority for research, action, and growth (ORG 33/001/2005).

Yet even for translation into the core languages, there were significant organisational differences under this former structure, for instance in the use of translation tools and guidelines. In terms of funding, EDAI and EFAI were mainly self-financed, whereas the Arabic translation team, operating from the IS in London, was financed by the IS. Translation into these three "core" languages was, and still is under the new AILRC structure, mainly done by professional translators. The translation practices into these languages contrasts markedly with translation practices into and from small non-core languages. Naturally, this enhances differences in terms of translation quality, speed, and terminology consistency. Under the structure of core versus noncore languages, the different translation services rarely cooperated or exchanged best practices. These are the areas in which the AILRC aims to make improvements.

\subsection{The Language Resource Centre}

Key to implementing successfully the language strategy of One Amnesty is to increase cooperation between sections and translation teams, and to liaise working procedures (ORG 33/002/2010). As described above, cooperation between different language services was limited before the establishment of the AILRC. The IS's knowledge of what sections are actually doing in the area of translation is also limited, and thus one of the main tasks of the AILRC is to collect information on translation practices at the various sections.

The term Centre can be somewhat misleading: the structure of the AILRC should rather be understood as a virtual network operated from different locations. The AILRC Director is located at the EDAI premises, renamed AILRC-ES from 2011 onwards. This office also functions as the AILRC's head office. Rooted in the One Amnesty approach, the AILRC aims to integrate all of the existing language teams and to create a single, tangible team of specialists, grouping language functions 
together under the same umbrella and coordinating their activities throughout the organisation. Thus, the Centre's structure is based on functions rather than on geographical locations (ORG 33/002/2010). For example, instead of having a person in charge of terminology in each office for each individual language, the Centre appoints one terminology manager. The Centre faces a number of challenges, amongst them the demand to expand the language service on a tight budget, to invest less in the traditional language services in order to be able to fund the One Amnesty priorities, and to embed the language strategy in the new structure of decentralised hub offices. Figure 2 presents the AILRC's organisation structure in 2012, together with the language services that had been incorporated into the AILRC at that time.

\section{FIGURE 2}

Organisation structure of AILRC (2012)21

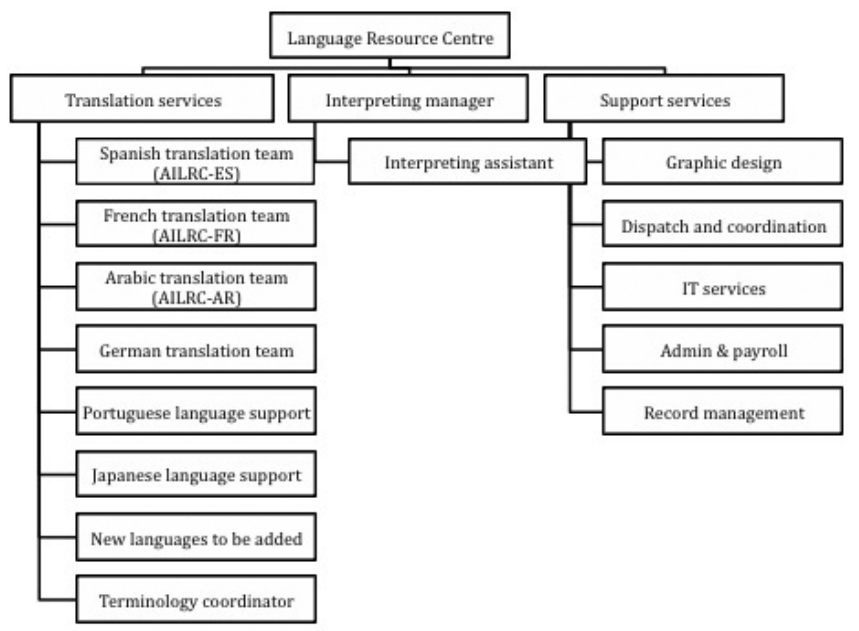

As noted above, one of the main challenges of the AILRC is to liaise working procedures between the different services. Indeed, as represented in this structure, a reasonable expectation is that the services would maintain the same translation practices and procedures to a great extent. Yet this is not the case, given the units developed separately from each other. For example, AILRC-FR and AILRC-ES use different translation tools. This goes back to decisions made on the basis of the particular needs of the separate units. Whereas EFAI found that texts contained many repetitions and their translation work would benefit from using a translation memory, EDAI started using a terminology tool before using a translation memory. EFAI chose to work with WordFast, since it responded to a number of criteria (such as easy use and good compatibility with other tools) and the tool provider agreed to offer a number of free licenses given the nature of AI's work. EDAI, however, started by using MultiTerm, the tool that best answered its needs at the time, and logically moved on to use Trados when it felt the need to start using a translation memory in 2010. ${ }^{22}$ These examples show how units have developed independently, with each unit having its own way of working. Naturally, coordinating the use of translation tools is one of the many problems that the AILRC is facing at the moment. It will take considerable time and effort before the Centre succeeds in liaising the main working procedures, let alone providing support to small translating languages such as Dutch. More time, effort, and resources are needed to exploit the possibilities of language and translation as strategic tools to increase AI's impact and success. 


\section{Concluding remarks}

This article has demonstrated that whereas IGOs and NGOs may both have institutional multilingualism built into their language policies, the ways in which it is put into practice can differ greatly. It has looked at how multilingualism is defined by both types of organisations, and how the concepts of official and working languages are used in policy documents. By exploring Amnesty International as a case study, it has been shown that language in this particular NGO is used as a strategic tool to increase the organisation's impact and growth, rather than as a symbolic tool to express equality. Moreover, it demonstrated how the NGO moved away from the more traditional understanding of multilingualism as foundational to the use of strategic multilingualism. Although it has been pointed out that foundational multilingualism tends to be highly resistant to change, this is not the case for AI. The move away from foundational multilingualism is directly related to the nature of AI as an organisation: it has limited funds available for translation, yet it needs to increase its impact and growth to remain relevant as a human rights NGO.

Using internal policy documents and data from fieldwork, the article has mainly focused on the institutional framework of multilingualism. The way multilingualism has been put into practice was described for AI's "official" or "strategic" languages, and some of the implications for non-strategic and small languages have been discussed. Some further remarks can be made on the use of translation as a strategic tool and possible consequences related to this.

It is noteworthy that AI's language policy does not explicitly mention a translation policy. As pointed out above, translation policy arises as a consequence of decisions taken on language policy. Thus, AI's initial decision to communicate in Arabic, French, and Spanish as official languages in addition to English necessitated the creation of translation services for these three languages. Choosing not to translate into other, often smaller, languages also brings with it particular consequences. This choice has created major differences in the organisation of translation into the strategic and tactical languages, versus the remaining languages. For the latter, translation practices remain much more unregulated and diverse. Such a discrepancy has consequences for AI's impact worldwide. As demonstrated in Tesseur (2013), a translation policy that allows for differing translation practices also leads to differences in the translation products. Some local sections take much greater liberties when translating than the translation services of AILRC.

As mentioned at the beginning of this paper, the use of the concept of translation policy here is similar to the traditional understanding of policy, and mainly refers to laws and regulations that have been documented as explicit policy. This was a logical choice, since policy documents have been the main source of data, especially AI's language policy and strategy dated 2007. However, the analysis made clear that in addition to explicit policy, there are many implicit policies that contribute to how translation within AI is regulated. Many small non-strategic and non-tactical languages initiate their own translation work, and thus also take their own translationrelated decisions. They implement, so to speak, their own local translation policies. This leads to two conclusions. Firstly, speaking of one translation policy for the whole of AI is inappropriate. Secondly, in order to study how language and translation are regulated throughout the organisation, working with a narrow definition of transla- 
tion policy implies missing out on many factors that contribute to the regulation of translation. When looking at explicit policy as written down in policy documents, analysis can only include the top-layer of how translation is regulated, or how it is set out to be regulated. The policy documents focus on translation into the official or strategic languages, and contain hardly any information on how translation into other languages should be dealt with, or to what extent translation into these languages should be provided.

Using a broader definition of translation policy that comprises translation management, practices, and beliefs (see Spolsky 2004) would cast more light on why such differing translation regulations exist throughout this particular organisation, and what implications they have for the representation of AI's message and voice in many languages around the world. Especially in light of the One Global Amnesty restructuring, the question about message and voice is vital. Given that the IS is losing control over the contents of documents that are generated, it is important for the organisation to have insight into and understanding of what sections are doing in terms of translation, but also how they conceptualise what translation is and where it is needed. Further research will explore how the changes in the language strategy at AI influence the status attached to translation throughout the organisation. As language and translation have become a central part of AI's growth strategy, the expectation is that the status of translation will have increased as well. Lastly, the present article has used AI as a case study; further research could explore whether the translation policies and practices described here are comparable to those of other NGOs.

\section{NOTES}

1. Macmillan Dictionary. "Policy.”Visited on 24 March 2014, <http://www.macmillandictionary. com/dictionary/british/policy/>.

2. United Nations. Article 111 of the Charter of the United Nations. Visited on 5 June $2013,<$ http:// www.un.org/en/documents/charter/chapter19.shtml>.

3. United Nations. $15^{\text {th }}$ Session of the General Assembly. Resolution 50/11. Multilingualism. Visited on 5 June 2013, <http://www.unlanguage.org/NewsDoc/Resolutions/Official\%20Languages/ Resolution_50\%2811\%29_Multilingualism.pdf $>$.

4. United Nations. Resolutions adopted on the reports of the Fifth Committee. Visited on 5 June 2013, <http://www.un.org/documents/ga/res/35/a35r219e.pdf>.

5. United Nations. UN at a Glance. UN official languages. Visited on 5 June 2013, <http://www. un.org/en/aboutun/languages.shtml>.

6. United Nations. Language Outreach by the United Nations. Official languages at the United Nations. Visited on 5 June 2013, <http://www.unlanguage.org/Careers/Interpret/COV/Languages/ default.aspx $>$.

7. Arabic, French, Russian, and Spanish translators are required to have excellent knowledge of at least two other official languages. English translators must also have excellent knowledge of at least two other official languages, one of which must be French. Chinese translators must have excellent knowledge of English; knowledge of an additional official language is desirable.

8. European Commission. Languages. Visited on 24 November 2014, <http://ec.europa.eu/languages/ policy/language-policy/official_languages_en.htm $>$.

9. The use of the concept "official languages" is problematic in the case of Amnesty International. The organisation did use the concept originally to refer to its use of Arabic, English, French, and Spanish, but moved away from it in 1994. See 3.2 for elaboration on this topic.

10. Peter Benenson (May 28Th, 1961). “The Forgotten Prisoners” The Observer. 21.

11. Amnesty International. The History of Amnesty International. Visited on 5 June 2013, <http:// www.amnesty.org/en/who-we-are/history>.

12. The information on Amnesty International's early language-related decisions and policies stems from the more recent AI internal document with reference number ORG 33/001/2005. Documents 
prior to 1993 can only be consulted in the archives. The present research data consists of documents from 1993 onwards, of which electronic versions are available on the intranet. These documents could be consulted during fieldwork at the three AI sections: AIVL, AILRC-ES and AILRC-FR.

13. For ethical reasons, interview data (AI Interview \#2, AI Interview \#3, AI Interview \#12) has been anonymised.

14. All Amnesty International documents have a unique index number. These numbers are used in the present article to indicate sources.

15. Amnesty International's Language Policy was documented in ORG 33/001/1987.

16. For more information on interpreting services at Amnesty International, see $<$ http://www.nationalnetworkforinterpreting.ac.uk/tasks/importance_of_interpreting/player. html>, Visited on 11 June 2013.

17. The Asian Language Program was set up as a temporary program in 1991 and was made permanent by an ICM decision in 1995. The Portuguese Language Program was established in 1994 after a 1993 ICM decision.

18. Amnesty International. Moving Closer to the Ground. Visited on 11 June 2013, <www.amnesty. org.uk/uploads/documents/doc_22399.doc>; AMNESTy INTERNATIONAL. Letter from International Executive Committee Chair Pietro Antonioli. Visited on 11 June 2013, $<$ http://www.amnesty.ie/sites/default/files/November\%202012\%20letter\%20to\%20Amnesty\%20 members\%20from\%20Pietro\%20Antonioli.pdf>.

19. The other communication strategies are the media strategy, the digital strategy, and the publishing, news, and knowledge and information strategies, all of which were developed between 2006 and 2011.

20. Urgent Actions are a type of Amnesty International documents that are intended for AI members and encourage them to write letters to particular political institutions or politicians to reconsider the fate of certain individuals whose human rights are being threatened.

21. Based on an organisational chart provided by AILRC.

22. Information from personal e-mail correspondence with staff from AILRC-ES and AILRC-FR in October 2013 and June 2014.

\section{REFERENCES}

Amnesty International (2013): Statute of Amnesty International. London: Amnesty International Publications. AI Index: POL 20/001/2013. Visited on 18 July 2014, <http://files. amnesty.org/AIStatute/AIStatuteAsAmendedAt2013ICM_EN.pdf>.

Arzoz, Xabier, ed. (2008): Respecting Linguistic Diversity in the European Union. Amsterdam/ Philadelphia: John Benjamins.

BAAIJ, Cornelis J.W. (2012): The EU Policy on Institutional Multilingualism: Between Principles and Practicality. Language \& Law. 1. Visited on 17 July 2014, <https://www.languageandlaw. de/volume-1/3338>.

BAIgORRI-JALón, Jesús (2004): Interpreters at the United Nations: A History. Salamanca: Ediciones Universidad de Salamanca.

CAO, Deborah and ZHAO, Xingmin (2008): Translation at the United Nations as Specialized Translation. The Journal of Specialised Translation. 9:39-54.

Cottle, Simon (2009): Global Crisis Reporting: Journalism in the Global Age. Maidenhead: Open University Press.

Cottle Simon, and Nolan, David (2007): Global Humanitarianism and the Changing AidMedia Field "Everyone was dying for footage." Journalism Studies. 8(6):862-878.

Cronin, Michael (2003): Translation and Globalization. London/New York: Routledge.

Cronin, Michael (2009): Globalization. In: Mona BAKer and Gabriela SAldanha, eds. Routledge Encyclopedia of Translation Studies. $2^{\text {nd }}$ ed. Milton Park/Abigdon: Routledge, 126-129.

Duchêne, Alexandre (2008): Ideologies Across Nations: The Construction of Linguistic Minorities at the United Nations. Berlin/New York: Mouton de Gruyter.

GonzÁLEz NúÑEz, Gabriel (2013): Translating for linguistic minorities in Northern Ireland: a look at translation policy in the judiciary, healthcare, and local government. Current Issues in Language Planning. 14(3-4):474-489.

Hopgood, Stephen (2006): Keepers of the Flame: Understanding Amnesty International. Ithaca/ London: Cornell University Press. 
Joscelyne, Andrew (2000): The role of translation in an international organization. In: Robert C. Sprung, ed. Translating into Success: Cutting-Edge Strategies for Going Multilingual in a Global Age. Amsterdam/Philadelphia: John Benjamins, 81-95.

Koskinen, Kaisa (2008): Translating Institutions: An Ethnographic Study of EU Translation. Manchester: St. Jerome.

Koskinen, Kaisa (2011): Institutional Translation. In: Yves Gambier and Luc Van Doorslaer, eds. Handbook of Translation Studies. Vol. 2. Amsterdam/Philadelphia: John Benjamins, 54-60.

LehtovaAra, Heini (2009): Working in Four Official Languages: The Perceptions of OGB Employees on the Role of Language in Internal Communication. Master thesis, unpublished. Helsinki: Helsinki School of Economics. Visited on 12 June 2013, <https://aaltodoc. aalto.fi/bitstream/handle/123456789/318/hse_ethesis_12186.pdf?sequence=1 >.

Meylaerts, Reine (2010): Multilingualism and Translation. In: Yves Gambier and Luc Van Doorslaer, eds. Handbook of Translation Studies. Vol. 1. Amsterdam/Philadelphia: John Benjamins, 227-230.

Meylaerts, Reine (2012): Translation Policy. In: Yves Gambier and Luc Van Doorslaer, eds. Handbook of Translation Studies. Vol. 2. Amsterdam/Philadelphia: John Benjamins, 163168.

O'Driscoll, Jim (2001): Hiding Your Difference: How Non-global Languages Are Being Marginalised in Everyday Interaction. Journal of Multilingual and Multicultural Development. 22(6):475-490.

Pум, Anthony (2001): The use of translation in international organizations. Translation and Institutions Workshop. $34^{\text {th }}$ annual meeting of the Societas Linguistica Europaea. Leuven, 2831 August 2001. Visited on 1 June, 2013, <http://usuaris.tinet.cat/apym/on-line/translation/ transinst.html>.

Pyм, Anthony (2008): Translation vs. Language Learning in International Institutions: Explaining the Diversity Paradox. Cultus. 1:70-83. Visited on 24 November 2014, http://cultusjournal. com/1/upload/anthony_pym.pdf.

Pyм, Anthony (2012): Machine Translation and Crowdsourcing. Sections to be added to Chapter 7 "Localization." Exploring Translation Theories. Visited on 1 June 2013, <http://usuaris. tinet.cat/apym/publications/ETT/added_sections_TM_MT.pdf>.

Sнонамy, Elena (2006): Language Policy: Hidden Agendas and New Approaches. London/New York: Routledge.

Spolsky, Bernard (2004): Language Policy. Cambridge: Cambridge University Press.

Stecconi, Ubaldo (2010): Multilingualism in the EU: A Developing Policy Field. In: Susan Bassnett and Christina Schäffner, eds. Political Discourse, Media and Translation. Newcastle: Cambridge Scholars Publishing, 144-163.

Tesseur, Wine (2013): Amnesty International's language strategy put into practice: a case study of the translation of press releases. In: Gabriel González NúÑEz, Yasmine Khaled and Tanya Voinova, eds. Emerging Research in Translation Studies: Selected Papers of the CETRA Research Summer School 2012. Visited on 23 March 2014, <http://www.arts. kuleuven.be/cetra/papers/files/tesseur>.

Tosi, Arturo, ed. (2003): Crossing Barriers and Bridging Cultures: The Challenges of Multilingual Translation for the European Union. Clevedon: Multilingual Matters.

UNION OF INTERNATIONAL ASSOCIATIONS (2014): Yearbook of International Organisations 20142015. Leiden/ Boston: Brill/ Martinus Nijhoff Publishers.

Wagner, Emma, Bech, Svend and Martínez, Jesús M. (2002): Translating for the European Union Institutions. Manchester: St. Jerome.

Wong, Wendy H. (2012): Internal Affairs: How the Structure of NGOs Transforms Human Rights. New York: Cornell University Press. 